\title{
Genre analysis of essays in the Social Sciences: The case of Botswana students
}

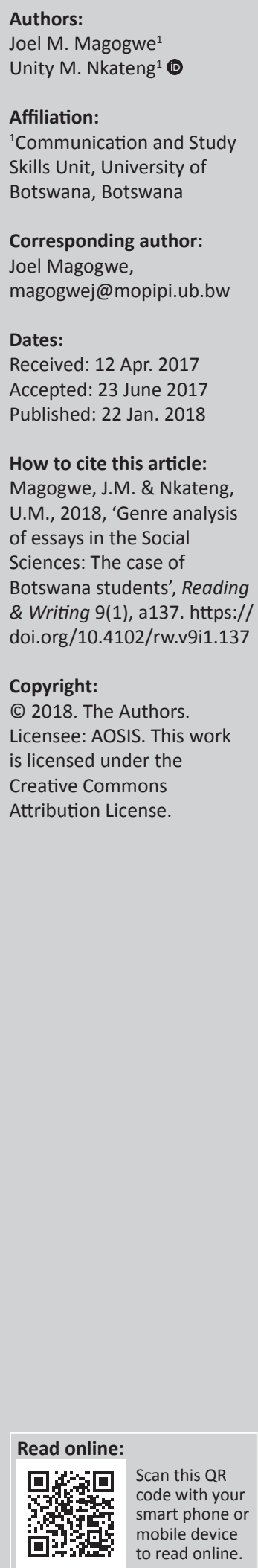

Writing is a challenging but requisite skill at university and other life situations. At university, essay writing is generally challenging to first-year students across disciplines or faculties. This study therefore describes the writing challenges of the Faculty of Social Sciences students at the University of Botswana. To that end, this study asks the following research questions: (1) What writing tasks are first-year students in the Faculty of Social Sciences given? (2) What problems do the students encounter when writing essays in the Faculty of Social Sciences? (3) What kind of assistance do students receive on writing essays? This article is underpinned by the English for Academic Purposes genre analysis framework. All in all, the findings of this study point to the need for a more intensive writing programme for first-year students at the University of Botswana in which both faculties and the Communication and Study Skills Unit will cooperatively assist students with writing. Students' responses clearly indicated the need for such collaboration.

\section{Introduction}

Writing is a challenging but requisite skill at university and other life situations. At university, essay writing is generally challenging to first-year students across disciplines or faculties (Ahmed 2010; Nesi \& Gardener 2012; Nkateng 2013). In the light of that, this study describes the writing challenges of the Faculty of Social Sciences students at the University of Botswana. At the University of Botswana, essays are written in English, the official medium of instruction at the university and other levels of education in Botswana. As second language learners, Botswana students across all levels struggle to write in English. To address this problem, the University of Botswana offers compulsory Communication and Study Skills courses to all first-year students. Briefly, these courses teach subject-specific academic and professional communication topics using relevant teaching and assessment approaches selected by the lecturers who teach them. These courses are informed by the English for Academic Purposes (EAP) discipline. To provide context for this study, it is important to note that Botswana is a Southern African country located between South Africa, Namibia and Zimbabwe.

\section{Literature review and theoretical framework}

This article is underpinned by the EAP genre analysis framework. EAP is a branch of the English for Specific Purposes (ESP) discipline (Robinson 1991). ESP is goal directed and propounds that learners do not learn the English language for the sake of it. They learn it because they use it in their specific professional or academic lives. EAP's foci are language and associated institutional and disciplinary practices, such as referencing and writing, which people need to undertake to study or work in English medium higher education. The main objective of EAP courses is to teach the language, both general academic language and subject-specific language, as well as languagerelated practices such as summarising and writing introductions. EAP courses usually focus on the process of writing - planning, organising, presenting, rewriting, and proofreading. Typical writing skills that are the foci of EAP include research and using sources, writing different text types as well as different genres and using an appropriate style with some degree of accuracy.

\section{Genre analysis}

Genre analysis has been defined by various scholars such as Miller (1984), who defines it as a classification of typified acts of communication (cited in Herring, Scheidt \& Wright 2004). However, this study is premised on one of the most influential researchers on genre analysis, John Swales, who, with his analysis of the rhetorical structure of the introductions of research articles, established a method for the analysis of the rhetorical structure of different genres (Luzon 2005). According to Swales (1990): 
A genre comprises a class of communicative events members of which share some set of communicative purposes. These purposes are recognised by the expert members of the parent discourse community, and thereby ... Communicative purpose is both privileged criterion... (p. 58)

Discourse community according to Swales (1990) refers to a community in which a particular type of written text is shared. Swales posits that in a discourse community, the language medium is mainly a written text, that the use of language is essentially functional and that in a discourse community people become members of the community of their own will. According to Swales (1990), examples of genre include research papers, essays, theses, letters, poems, recipes and news broadcasts. Many genre-based studies have analysed genre structure or the different rhetorical moves that conform to the genre, lexico-grammatical features or the function of tenses in the genre, the use of nominalisation, the type of vocabulary and textualisation or the conventional use of specific linguistic features in certain genres.

\section{Rationale and justification}

Rather than treat different disciplines as singular discourse communities with the same writing conventions, this study focuses solely on the Faculty of Social Sciences under the guarantee that most recent research has focused on tasks from a single discipline (e.g. Braine 1989; Carson 2001). Again, different researchers have found that there are different variations across disciplines (Bazerman 1981; Becher 1987). Furthermore, lecturers in different faculties of the universities expect students to write according to the expectations of their host faculties. Healey (2000:173) claims that 'there is a strong perception among [academic] staff that there are significant differences among disciplines in what academics do and how these activities are described and valued'.

According to Hyland (2000), students' needs must be clearly researched and it should be borne in mind that different subjects may have different needs at different levels in different institutions or countries. With that in mind, the authors of this article undertook this research with the objective of addressing the students' writing problems. Congruent with this objective is the notion that the central role of the EAP lecturer or course designer is to find out what learners need, what they have to do in their academic work or courses and help them to do that better in the time available. Secondly, EAP recognises that tertiary students possess different learning needs, which cannot be addressed by teaching them the same type of English language (Coffey 1984).

Notably, in some parts of the world, for over 20 years the types of writing tasks given to students have been examined in EAP context, especially in Science, Engineering and Business (Braine 1995; Davis 1998; Luzon 2005). But, as far as the authors of this study are concerned, there is no research similar to this one that has been conducted in Botswana.
This research thus sheds light on the written communication in the Social Sciences, and its findings contribute ideas on the design of academic writing skills syllabus for the Social Sciences and suggest where emphasis should be put when teaching. To that end, this study asks the following research questions:

- What writing tasks are first-year students in the Faculty of Social Sciences given?

- What problems do the students encounter when writing essays in the Faculty of Social Sciences?

- What kind of assistance do students receive on writing essays?

\section{Methodology}

Seventeen essays written by Faculty of Social Sciences firstyear students in their various departments were examined. The essays were reviewed and analysed using Swales's (1990) genre analysis framework of moves as a guide. Swales notes that there is a regular pattern of 'moves' and 'steps' that appear in a certain order in the majority of introductions investigated. A move then becomes 'a unit that relates both to the writer's purpose and the content that $\mathrm{s} /$ he wishes to communicate' and 'a step is a lower level text unit than the move' (DudleyEvans \& St. John 2003:89). Most importantly, the objective of this study was not to analyse the essays under investigation at the 'text' level but only at the level of the 'move'. To analyse the essays, the organisation of the whole essay and its sections were examined, the purpose and style of writing the essay were identified and language features were studied too. To cater for inter-rater reliability, the two authors first individually read the essays and identified emerging patterns in terms of the organisation of the essays, their purpose and style and language problems. Then the authors met, compared their assessments and came up with a rubric, which they then used again to re-scrutinise the essays.

The sample of students in this study was conveniently selected from the lecturers' classes. The students were conveniently sampled in the sense that they were easy to reach by their lecturers who are the authors of this study. There were no specific criteria required to select the students, and all those willing to submit their essays were encouraged to do so. Eleven of the 17 students were voluntarily engaged in face-to-face interviews to get their views, experiences and problems they encounter when writing essays. The lecturers announced that any students interested in participating in the interviews could volunteer but only 11 agreed. The openended interview questions asked the students to identify the writing assignments or tasks they were required to do in the Social Science Faculty, to indicate why they were or were not satisfied with their writing, to identify the problems they encountered when writing academically, how much and what kind of assistance they received in writing academic essays and what they thought could be done to assist them to improve their writing. For ethical considerations, the students were asked to volunteer to participate in the research and they were also assured that information obtained from their essays and interviews would not be divulged without their 
consent and that it would mainly be used for the purpose of this study. The interviews, each of which lasted for approximately $20 \mathrm{~min}$, were recorded and later transcribed by the authors.

\section{Limitations}

Firstly, the findings of this study should be accepted against the understanding that essay writing is not the only type of writing done in the Social Sciences. Other types of writing include reports, research papers, literature reviews and case studies.

Secondly, only first-year essays were analysed and issues of writing in the Social Sciences discussed in this article are confined to the findings from that level only. In addition, the essays reviewed in this study came from students from different departments of the Faculty of Social Sciences, and thus the findings are not subject-specific. As already indicated, the sample of students in this study was conveniently selected from the authors' classes.

\section{Findings and discussion}

What writing tasks are first-year students in the Faculty of Social Sciences given? First-year students who participated in this study gave divergent answers to this question, although they all agreed that most of the time they wrote essays for continuous assessment. One of the students summed this up by saying:

'We don't really do a lot of writing now, maybe in the future. I am not even quite sure about the kind of essays we write, but I think in future we will write an argumentative essay.' [Student A, Female, First Year]

Another one indicated that she was not sure about the types of essays they wrote, but they had been asked to discuss reasons why one of the political parties in Botswana engaged in some activities. Another student indicated that they did a lot of essay writing and that the type of writing tasks they did depended on the types of questions they wrote. Other students indicated that they were given essays where they had to define key terms, while others said they were given questions where they had to go out to collect data or research. All in all, 59\% $(n=10)$ of the 17 essays analysed were discussion type essays. Discussion essays require students to discuss issues surrounding a particular topic, usually that are debatable or open to argument. Given that students who participated in this study came from different departments within the Faculty of Social Sciences, it is possible that they were required to write different types of texts or essays in their various departments. However, it is important to note that almost all of those who were interviewed pursued the same programme of study, degree or academic plan.

Another objective of this study was to analyse the organisational structure of the essays in terms of purpose, style and language features. Ahmed (2010) states that a coherent essay consists of an introduction, a thesis statement, rhetorical support and a conclusion. The authors of this article expected that the students' essays would have all these three parts. All the 17 essays had an introduction, defined key words, provided relevant topics and provided a conclusion. Most essays were introduced with the following statements: 'the aim of this essay is ...' or 'the purpose of this essay is to ...'. Interestingly, in most essays, the purpose of the essay was not concordant with the development of the essay. These findings suggest that students need to develop the skill of writing creative introductions in order to make their essays more interesting or scholarly.

Students also confused essay writing with report writing. For example, in one essay the student wrote an abstract and called it an introduction. Another essay was subdivided like a research report with headings and subheadings such as 'abstract', 'introduction and background', 'theoretical framework', 'findings' and 'recommendations'. This suggests the need to ground the students in genre-based pedagogy so that they can distinguish the different writing genres in their discipline.

Ideas in all the essays were incoherent and not well developed. The paragraphs were not properly linked or cohesive. One of the interviewees indicated that 'I need help with writing coherently and sometimes I drift from one topic to another'. According to Ahmed (2010):

producing a coherent piece of writing is an enormous challenge, especially in one's second language. This is magnified by the fact that the rhetorical conventions of English texts - the structure, style, and organization - often differ from those in other languages. (p. 211)

It seems that the Faculty of Social Sciences students need guidance on the process of writing and that feedback should be given during each stage of the process so that the students can appreciate the systematic development or unfolding of ideas during the writing process. One of the interviewees indicated that they only got feedback after marking or when they were asked to resubmit the essay. Therefore, stage-bystage feedback is highly recommended.

In so far as writing perceptions are concerned, students claimed to be coping well, although they identified a number of areas where they needed assistance. These include: 'understanding the topic', 'quoting', 'paraphrasing', 'referencing', 'arranging ideas', 'insufficient vocabulary' and 'linking paragraphs'. One student said:

'I need more help in referencing and paraphrasing, and I really find it difficult to use my own words.' [Student B, Male, First Year]

At the micro-level, the omission of words in the essays showed that students did not proofread their essays before submitting them. For example:

'These youth face many $\wedge$ while they are in sex work industry.' [Student C, Female, First Year $]^{1}$

1.This symbol (^) means that the student omitted information 
Some essays contained informal language such as that used in oral presentations. For example,

'These young sex workers don't go to hospitals because they fear the horrifying experiences they'll receive. After all they are humans like we are.' [Student D, Female, First Year]

Plagiarism was another common problem in the essays, and students did not acknowledge their sources.

Finally, this study sought to find out how much assistance students received in writing essays. One student indicated that their Public Administration tutor taught them how to format an essay and how to interpret an essay question. Another student said:

'This semester we were given an assignment in Political Science and I was assisted by a third year student on referencing. At the library we met somebody who told us the same thing.' [Student B, Female, First Year]

The same student indicated that she was happy that their Communication Skills Lecturer gave them a passage and asked them to reference and paraphrase. The third student indicated that their Communication Skills Lecturer 'took us to the library and gave us detailed information on how to use the library and the internet, but our Public Administration tutor just explained the topics'. A fourth one claimed that:

'I have never been helped in Political Science, but in Communication Skills I don't think we have touched on writing. Definitely Communication Skills and Political Science should work together to improve our essay writing.' [Student D, Female, First Year]

The fifth student said:

'I don't think what is being done is good enough, we need more time on writing. More time is being given to presentations in Communication Skills.' [Student E, Male, First Year]

Finally, the sixth student said:

'I don't think our Public Administration tutor and Communication Skills lecturer are working together. They assume that one is covering what the other is not covering in class.' [Student F, Male, First Year]

These findings suggest that writing support given to firstyear students should be more organised. This further suggests the need for collaboration between the Faculty of Social Sciences and the Communication and Study Skills Unit (CSSU), which offers academic writing advice.

In summary, the findings of this study show that first-year Faculty of Social Science students who participated in this study confirmed that they wrote essays more than other types of writing. Although students perceived their writing to be generally good, the findings suggest that they confused essay writing with other forms of writing such as report writing. They also acknowledged making writing errors, most of which included challenging skills of paraphrasing, quoting and referencing. Other common writing problems at the University of Botswana related to paraphrasing are overlong sentences normally caused by comma-splices, runon ideas and redundancy. These sentence writing problems seem to be caused by mother tongue interference in writing. All in all, the findings of this study point to the need for a more intensive writing programme for first-year students at the University of Botswana in which both faculties and the CSSU will cooperatively assist students with writing. Students' responses clearly indicated the need for such collaboration.

\section{Implications}

Several implications arise from the findings of this study. Firstly, the students were asked to identify different types of writing they did in their faculty or respective departments. As shown in the findings section, they gave divergent answers to this question, although they all agreed that most of the time they wrote essays for continuous assessment. This suggests that the students were not well acquainted with the various writing genres in their discipline. In order to address this confusion, it is important to make the students aware right at the beginning of their studies that different courses require different written assignments. Zhu (2004) shares the same sentiment.

In addition to raising awareness about the different genres, students should be familiarised with differences between these written academic genres. The analysis of the essays in this study showed that some students used the report writing rhetorical mode or style to write an essay. They should, therefore, be made aware that different genres require different structures (e.g. abstracts, introductions and sections) and linguistic devices (e.g. words showing the writer's stand or identity). This proposition is supported by Dudley-Evans and St. John's (2003) assertion that:

In the academic context, students are required to produce specific writing genres such as essay, summary, critical review $\ldots$ and focus on the distinguishing regularities of structure of different text types can help learners build a repertoire of the organization and the relevant language forms of different genres. (Al-Khasawneh \& Maher 2010:2)

Students should also be made aware of the nature of audience for which different genres are written. For example, they should be aware that academic writing style is for the academic community (such as lecturers and peers) and that professional writing style is used for the professional audience (or non-academic readers). To support the above suggestion, Zhu (2004) asserts:

It is important to teach second language learners how to write for different audiences, academic and non-academic, and help them develop the ability to organize and present information based on an assessment of audience needs. (p. 132)

Students should also be made aware of common English as Second Language (ESL) writing errors or problems such as 'understanding the topic', 'quoting', 'paraphrasing', 
'referencing', 'arranging ideas', 'lack of vocabulary' and 'linking paragraphs'.

Awareness-raising on its own may not be sufficient to address students' essay writing problems. Establishing collaboration between Faculty of Social Sciences content lecturers and CSSU lecturers offering EAP courses may bring another solution to the writing problems. This is because lack of collaboration may cause confusion for the students in terms of conflicting and contrasting specific writing requirements from content lecturers and CSSU lecturers. The findings of this study showed that the support students were getting from their faculty needed to be more organised and that the CSSU should provide support that addresses specific writing needs of the students. In a similar study, Lea and Street (1998) conducted interviews in which learning support staff questioned whether academic staff was aware that they were asking for specific ways of writing knowledge from their students. Similarly, collaboration can also be encouraged between students themselves. For instance, Zhu (2004) posits that:

Writing courses and instructors could help second language learners further develop teamwork skills. In cooperative groups, members must know how to negotiate a common task as well as their individual responsibilities, how to provide input and feedback on others' work, and how to reach consensus when conflicts arise.

Finally, in conjunction with content lecturers, it is imperative for the CSSU to develop writing materials that will help the Faculty of Social Sciences learners acquire some of the genres that they will be required to understand and eventually produce as part of their academic studies or research. Based on this analysis, they could design EAP teaching materials, which would enable students to use certain linguistic and stylistic strategies that could enable them to become accepted members of their discourse communities.

\section{Conclusions and recommendations}

The findings of this study have unearthed very important issues that need to be considered in an attempt to provide writing support for the Social Sciences ESL students and by extension students from all university faculties. Firstly, the findings showed the need to raise students' awareness of different writing genres and their integral differences and uses. Secondly, a more organised writing course is imperative through collaboration between content lecturers and CSSU lecturers. The two should conduct a needs assessment and syllabus review and use the results to design a fully fledged writing skills course for Social Science students and by extension for all faculties. For example, the analysis of essays in this study revealed that there was a need for students to be taught referencing, in-text citations and the use of paraphrasing. This study further recommends research investigating types of writing done in all faculties of the University of Botswana and in all departments in each faculty. The research may unearth the discrepancies existing between content courses and EAP in terms of the type of content and relevant approaches of teaching the essays and other writing genres. This interdisciplinary research can be conducted by both content lecturers and CSSU lecturers.

\section{Acknowledgements}

We are deeply indebted to students who participated in this study as respondents and to colleagues who offered advice during the conference where this article was presented. This study would not have been possible without their help.

\section{Competing interests}

The authors declare that they have no financial or personal relationships that may have inappropriately influenced them in writing this article.

\section{Authors' contributions}

Both J.M.M. and U.M.N. agreed to write on this topic and to design the study. U.M.N. was responsible for collecting the data after both of them had agreed on the method and procedure of data collection. Both of them analysed the data. J.M.M. was more responsible for putting the article together, and both of them edited and finalised it.

\section{References}

Ahmed, A.H., 2010, 'Students' problems with cohesion and coherence in EFL essay writing in Egypt: Different perspectives', Literacy Information and Computer Education Journal (LICEJ) 1(4), pp. 211-221. https://doi.org/10.20533/ licej.2040.2589.2010.0030 211-221

Al-Khasawneh, F.M.S. \& Maher, S., 2010, 'Writing for academic purposes: Problems faced by Arab postgraduate students of the college of business, UUM', ESP World 9(2), 1-23.

Bazerman, C., 1981, 'What written knowledge does: Three examples of academic discourse', Philosophy of the Social Sciences 11, 361-388. https://doi.org/ $10.1177 / 004839318101100305$

Becher, T., 1987, 'Disciplinary discourse', Studies in Higher Education 12, 261-274. https://doi.org/10.1080/03075078712331378052

Braine, G., 1989, 'Writing in science and technology: An analysis of assignments from ten undergraduate courses', English for Specific Purposes 8, 3-16. https://doi. org/10.1016/0889-4906(89)90003-3

Braine, G., 1995, 'Writing in the natural sciences and engineering', in D. Belcher \& G. Braine (eds.), Academic writing in a second language, pp. 113-134, Ablex Publishing Corporation, Norwood, NJ.

Carson, J., 2001, 'A task analysis of reading and writing in academic contexts', in D. Belcher \& A. Hirvela (eds.), Linking literacies: Perspectives on L2 reading-writing connections, pp. 48-83, The University of Michigan Press, Ann Arbor, MI.

Coffey, B., 1984, 'State of the art article - English for specific purposes', Language Teaching 17(1), 2-16. https://doi.org/10.1017/S0261444800010405

Davis, T.M., 1998, Open doors 1997/98: Report on international educational exchange, Institute of International Education, New York.

Dudley-Evans, T. \& St. John, M.J., 2003, Developments in ESP. A multi-disciplinary approach, Cambridge University Press, Cambridge.

Healey, M., 2000, 'Developing the scholarship of teaching in higher education: A discipline based approach', Higher Education Research and Development 19, 169-189. https://doi.org/10.1080/072943600445637

Herring, S.C., Scheidt, L.A., Bonus, S. \& Wright, E., 2004, 'Bridging the gap: A genre analysis of weblogs', in Proceedings of the 37th Annual Hawaii International Conference on System Sciences, 2004, January, IEEE, January 5-8, 2004, pp.11-21

Hyland, K., 2000, Disciplinary discourses: Social interactions in academic writing, Longman, London.

Lea, M. \& Street, B., 1998, 'Student writing in higher education: An academic literacies approach', Studies in Higher Education 23(2), 157. https://doi.org/10.1080/03075 079812331380364

Lea, M. \& Street, B., 2006, 'The "academic literacies" model: Theory and applications', Theory into Practice 45(4), 368-377. https://doi.org/10.1207/ s15430421tip4504_11

Luzon, M.J., 2005, 'Genre analysis in technical communication', IEEE Transactions on Professional Communication 48(3), 285-295. https://doi.org/10.1109/ TPC.2005.853937 
Miller, C.R., 1984, 'Genre as social action', Quarterly Journal of Speech 70, 151-167. https://doi.org/10.1080/00335638409383686

Nesi, H. \& Gardner, S., 2012, Genres across the disciplines: Student writing in higher education, Cambridge University Press, Cambridge.

Nkateng, U., 2013, 'An investigation into written genres used by professional social workers and taught to social work students in Botswana', unpublished $\mathrm{PhD}$ thesis, University of Warwick.
Robinson, P., 1991, ESP today: A practitioner's guide, Prentice Hall International (UK) Ltd, Prentice Hall, UK.

Swales, J.M., 1990, Genre analysis, Cambridge University Press, Cambridge.

Zhu, W., 2004, 'Writing in business courses: An analysis of assignment types, their characteristics, and required skills', English for Specific Purposes 23, 111-135. https://doi.org/10.1016/S0889-4906(02)00046-7 